\title{
WILEY-VCH
}

DOI: $10.1002 /(($ please add manuscript number $))$

Article type: Communication

\section{Room-temperature formation of highly crystalline multication perovskites for efficient, low-cost solar cells}

Taisuke Matsui ${ }^{a}{ }^{\dagger}, J i$-Youn Seo ${ }^{b} \leftarrow$, Michael Saliba ${ }^{b}$, Shaik M Zakeeruddin ${ }^{b}$ and Michael Grätzel $^{b^{*}}$

$\dagger$ These authors have contributed equally to the work.

a Advanced Research Division, Advanced Functional Materials Research Group, Panasonic Corporation, 1006 Kadoma, Kadoma City, Osaka 571-8501, Japan

${ }^{\mathrm{b}}$ Laboratory of Photonics and Interfaces, École polytechnique fédérale de Lausanne, Station 6, 1015 Lausanne, Switzerland

E-mail: michael.graetzel@epfl.ch

Keywords: perovskite solar cells, room temperature perovskite

Lead halide $\mathrm{APbX}_{3}$ based perovskite solar cells (PSCs) continue to attract large attention exhibiting currently a certified efficiency of $22.1 \%^{[1]}$, exceeding that of commercial polycrystalline silicon solar cells ${ }^{[2]}$. This has prompted recent strong interest in the development of PSCs for large-scale practical deployment. Since PSCs can be manufactured by solution methods, judicious process design is of primary concern for commercialization, targeting especially lower cost methods compared with other solar cells. However, state of the art perovskite materials such as $\mathrm{MAPbI}_{3}$ or $\mathrm{FAPbI}_{3}$ (where MA is methylammonium, $\mathrm{CH}_{3} \mathrm{NH}_{3}{ }^{+}$and FA is formamidinium. $\mathrm{CH}_{2}\left(\mathrm{NH}_{2}\right)_{2}{ }^{+}$) that are mostly used for PSCs need annealing at $70-150^{\circ} \mathrm{C}$ for $30-60$ minutes to form the black crystalline photoactive layer ${ }^{[3-5]}$. This process is not suitable for mass production. Considering the roll-to-roll fabrication that is a very attractive way for mass production, the 30-60 minutes annealing process not only decreases throughput but also requires large processing areas and annealing equipment, apart from consuming energy. One way to address this problem is to employ an instant flash annealing technique as reported by J.Troughton et al. who used NIR heating or photonic flash sintering $^{[6,7]}$. 


\section{WILEY-VCH}

Another approach is to avoid the annealing step altogether. Recently, there are several reports appeared on cation combinations such as FA and Cs and/or MA perovskite formulations to yield black photoactive perovskite phase without annealing ${ }^{[8,9]}$. PSCs have been prepare at RT with efficiency of $15-17 \%^{[10,11]}$. However this method involves replacing the high boiling point dimethyl formamide (DMF) or dimethyl sulfoxide (DMSO) by a volatile solvent, which is not attractive from the practical point of view.

Here we show that Cs ions in combination with MA facilitate greatly the rapid room temperature crystallization of perovskites and explore its role in enhancing crystal formation. The device with optimized A-cation composition of $\mathrm{FA}_{0.8} \mathrm{MA}_{0.1} \mathrm{Cs}_{0.1}$ showed a solar to electric power conversion efficiency (PCE) of 18.1\% (stabilized at $17.7 \%$ ). Our method provides an attractive path to room temperature fabrication of PSCs by low-cost, large-scale manufacturing such as the roll-to-roll process.

We investigate FA/MA/Cs triple cation formulations for room temperature perovskite since they form high efficiency PSCs ${ }^{[9,12-15]}$ and low temperature, photoactive perovskite phase ${ }^{[8,9,16]}$ with combination of FA/MA, FA/Cs or FA/MA/Cs. To investigate the effect of cations, we fixed the FA:(MA+Cs) ratio as 0.8:0.2 and Br:I ratio as 0.83:0.17 and varied the MA:Cs ratio. For convenience, we describe the $\left(\mathrm{FA}_{0.8} \mathrm{MA}_{0.2-\mathrm{x}} \mathrm{Cs}_{\mathrm{x}}\right) \mathrm{Pb}\left(\mathrm{I}_{0.83} \mathrm{Br}_{0.17}\right)_{3}$ perovskite formulations as $\mathrm{FA}_{0.8} \mathrm{MA}_{0.2-\mathrm{x}} \mathrm{Cs}_{\mathrm{x}}$. Figure 1a shows the effect of the MA/Cs ratio on the photoluminescence (PL) emission spectra and UV-vis absorption spectra of the room temperature (RT) processed perovskite films. We spin coated the films and kept it for $5 \mathrm{~min}$ at room temperature. For comparison, we annealed in a similar way films at $100^{\circ} \mathrm{C}$ for $30 \mathrm{~min}$. The data in Figure 1a indicate a clear blue shift in the absorption and PL with increasing Cs content, due to lattice contraction by the small Cs ions while the Cs-free non-annealed $\mathrm{FA}_{0.8} \mathrm{MA}_{0.2} \mathrm{Cs}_{0}$ sample is not fully converted to the perovskite phase at RT. This confirms that mixed cations FA/MA/Cs are incorporated in the perovskite lattice. 


\section{WILEY-VCH}

Figure 1b shows the x-ray diffraction (XRD) patterns of the perovskite to vary with the MA/Cs ratio for the RT processed films. As shown in our previous study ${ }^{[9]}$, the (110) peak exhibits a strong intensity compared to annealed Cs-free films (Figure S1). However, upon increasing the $\mathrm{Cs} / \mathrm{MA}$ ratio, the relative intensity of the (112) peak is increased. This indicates that larger amounts of Cs affect the crystal orientation, which is unfavourable for the device performance ${ }^{[17]}$. The same tendency is shown in the un-annealed films.

On the other hand, for un-annealed films, formulations with less than $10 \%$ Cs exhibit several peaks between 5-10 degrees in the XRD patterns, arising from an intermediate $\mathrm{MA}_{2} \mathrm{~Pb}_{3} \mathrm{I}_{8} \cdot 2 \mathrm{DMSO}$ phase (Figure S2) ${ }^{[18]}$. This indicates that films with less than $10 \% \mathrm{Cs}$ are not fully converted to perovskite at RT. Also, these formulations contain some yellow $(\delta)$ phase of $\mathrm{FAPbI}_{3}$, which is undesirable for photovoltaic applications. Importantly, upon addition of $10 \% \mathrm{Cs}$, the $\delta$-phase completely vanishes. Thus we conclude that a minimum amount of $10 \%$ Cs is needed to stabilize the photoactive black phase ( $\alpha$-phase) for FA/MA/Cs triple cation perovskite formulations.

Figure 1c and Figure 1d show thermogravimetric analysis (TGA) data to detect any residual solvent, which is especially important for non-annealed films. Interestingly, the RT Cs-free $\left(\mathrm{FA}_{0.8} \mathrm{MA}_{0.2} \mathrm{Cs}_{0}\right)$ films show large amount of weight loss starting from around $70^{\circ} \mathrm{C}$, which corresponds to the evaporation temperature of DMF and DMSO ${ }^{[19]}$. However, the containing un-annealed films with the composition $\mathrm{FA}_{0.8} \mathrm{MA}_{0.1} \mathrm{Cs}_{0.1}$ and $\mathrm{FA}_{0.8} \mathrm{MA}_{0} \mathrm{Cs}_{0.2}$ display almost no weight loss similarly to the annealed film. This indicates that the Cs containing films contain almost no residual solvent in good agreement with the XRD data. We speculate that $\mathrm{Cs}$ interacts strongly with the $\left[\mathrm{PbI}_{6}\right]^{4-}$ octahedra ${ }^{[8]}$ replacing the intercalated solvent. In the absence of Cs the perovskite undergoes strong complexation by DMSO forming a stable DMSO-PbI 2 or MAI-DMSO-PbI ${ }_{2}$ complexes ${ }^{[20]}$ from which it is hard to remove the solvent (Scheme 1). To confirm this hypothesis, we conducted FTIR for $\mathrm{FA}_{0.8} \mathrm{MA}_{0.2-\mathrm{x}} \mathrm{Cs}_{\mathrm{x}}$ perovskite precursor solutions to see the intermolecular interactions in the 


\section{WILEY-VCH}

solution state. Figure $1 \mathrm{~d}$ shows that $\mathrm{N}-\mathrm{H}$ stretching at $3300-3500 \mathrm{~cm}^{-1}$ becomes stronger when the $\mathrm{Cs}^{+}$is added to FA/MA perovskite precursor solution. This corresponds to hydrogen bonding interaction $\left(\mathrm{N}^{+}-\mathrm{H} \cdots \mathrm{I}\right)$ between the organic salts $\left(\mathrm{MA}^{+} / \mathrm{FA}^{+}\right)$and iodide of the $\left[\mathrm{PbI}_{6}\right]^{4-}$ octahedra. ${ }^{[11]}{ }^{[21,24]}$ This causes a contraction of the distance of adjacent $\left[\mathrm{PbI}_{6}\right]^{4-}$ octahedral even in the solution state. Thus, we conclude that Cs helps not only stabilizing the $\alpha$-phase but also prevents incorporation of solvent, facilitating the room temperature crystallization of the perovskite phase.

Figure 2 shows the scanning electron microscope (SEM) images of $\mathrm{FA}_{0.8} \mathrm{MA}_{0.2-\mathrm{x}} \mathrm{Cs}_{\mathrm{x}}$ films for various $\mathrm{Cs}$ contents and $\mathrm{FA}_{0.9} \mathrm{MA}_{0} \mathrm{Cs}_{0.1}$ before annealing. The grain size of perovskite crystal becomes larger and larger with increasing the MA/Cs ratio. To investigate whether this effect comes from MA or not, we prepared also the MA-free $\mathrm{FA}_{0.9} \mathrm{MA}_{0} \mathrm{Cs}_{0.1}$ film. Comparing $\mathrm{FA}_{0.9} \mathrm{MA}_{0} \mathrm{Cs}_{0.1}$ and $\mathrm{FA}_{0.8} \mathrm{MA}_{0.1} \mathrm{Cs}_{0.1}$, we can see larger crystal in $\mathrm{FA}_{0.9} \mathrm{MA}_{0} \mathrm{Cs}_{0.1}$. In addition, the film with MA $\left(\mathrm{FA}_{0.8} \mathrm{MA}_{0.1} \mathrm{Cs}_{0.1}\right)$ has less full width with half maximum (FWMH) value of (110) peak from XRD pattern than that of the film without MA $\left(\mathrm{FA}_{0.9} \mathrm{MA}_{0} \mathrm{Cs}_{0.1}\right)$, which indicates film with MA has better crystallinity (Figure S3). Thus we conclude that MA helps to increase the grain size and crystallinity, probably due to interaction with $\mathrm{DMSO}^{[20]}$. Therefore, especially in non-annealed perovskite, both Cs and MA are necessary to convert the precursor to a pure photoactive perovskite phase of high quality crystals.

To investigate the solar cell performance, we used a device stack consisting of fluorine doped tin oxide (FTO)/compact $\mathrm{TiO}_{2} /$ mesoporous $\mathrm{TiO}_{2} /$ triple cation perovskite/2,2',7,7'tetrakis( $N, N$-di- $p$-methoxyphenylamine)-9-9'-spirobifluorene (spiro-OMeTAD)/Au. Figure 3a shows the cross sectional image of the device. All fabrication details can be found in the SI. Figure 3b shows the dependence of the photovoltaic performance on the MA/Cs ratio with and without annealing. Interestingly, mixtures of MA with Cs with annealed and un-annealed devices obtained the highest PCE. This tendency was more pronounced for un-annealed devices in line with the results from our XRD and SEM measurements discussed above. 


\section{WILEY-VCH}

Figure 3c presents current density-voltage $(\mathrm{J}-\mathrm{V})$ curves of the best RT device with the composition $\mathrm{FA}_{0.8} \mathrm{MA}_{0.1} \mathrm{Cs}_{0.1}$ under standard $\mathrm{AM} 1.5 \mathrm{G}$ sunlight at $100 \mathrm{~mW} / \mathrm{cm}^{2}$. The PCE derived from the $\mathrm{J}-\mathrm{V}$ curve scanned in forward bias direction was $18.1 \%$ with an open-circuit voltage $\left(\mathrm{V}_{\mathrm{oc}}\right)$ of $1155 \mathrm{mV}$, a short-circuit current density $\left(\mathrm{J}_{\mathrm{sc}}\right)$ of $21.5 \mathrm{~mA} / \mathrm{cm}^{2}$, and a fill factor (FF) of 0.73 , The power output was stabilized at $17.7 \%$ PCE. This is the highest PCE reported so far for a PSC prepared at room temperature. Also surprisingly, there is only a $0.6 \%$ difference to annealed PSCs. In order to investigate its long-term shelf-life, we stored the device in dark and dry air condition for 300 hrs (Figure S7). We confirmed there is no serious degradation, the relative value being $10 \%$ loss after $300 \mathrm{hrs}$ storage.

We also prepared room temperature perovskite on planar substrate with $\mathrm{SnO}_{2}{ }^{[25]}$ as electron selective contact deposited by ALD and achieved a PCE of $17.3 \%$ with a $\mathrm{V}_{\mathrm{oc}}$ of $1129 \mathrm{mV}$, a $\mathbf{J}_{\mathrm{sc}}$ of $22.4 \mathrm{~mA} / \mathrm{cm}^{2}$, and a FF of 0.68 derived from a forward scan and a stabilized 17.0\% PCE as shown in Figure 3d. This simple architecture employing

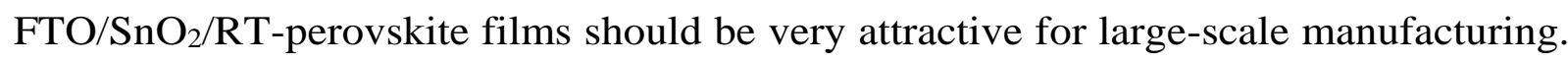

We studied examined the effect of Cs and MA in FA based PSCs on the room temperature crystallization of mixed cation perovskites. The presence of both Cs and MA was necessary to obtain the photoactive crystalline perovskite phase and high quality crystals. Remarkably by using optimized cation mixture of $\mathrm{FA}_{0.8} \mathrm{MA}_{0.1} \mathrm{Cs}_{0.1}$, we achieved a PCE of $18.1 \%$ (stabilized at $17.7 \%$ ) without annealing or any post treatment. The perovskite material shows great potential for low-cost, large-scale manufacturing such as roll-to-roll process. 


\section{WILEY-VCH}

\section{Experimental Section}

Substrate preparation and $\mathrm{Li}$-doping $\mathrm{TiO}_{2}$ Nippon Sheet Glass $10 \Omega / \mathrm{sq}$ was cleaned by sonication in $2 \%$ Hellmanex water solution for 30 minutes. After rinsing with deionised water and ethanol, the substrates were further cleaned with UV ozone treatment for $15 \mathrm{~min}$. Then, $30 \mathrm{~nm} \mathrm{TiO}_{2}$ compact layer was deposited on FTO via spray pyrolysis at $450^{\circ} \mathrm{C}$ from a precursor solution of titanium diisopropoxide bis(acetylacetonate) in anhydrous ethanol. After the spraying, the substrates were kept at $450^{\circ} \mathrm{C}$ for $45 \mathrm{~min}$ and left to cool down to room temperature. Then, mesoporous $\mathrm{TiO}_{2}$ layer was deposited by spin coating for $20 \mathrm{~s}$ at $4000 \mathrm{rpm}$ with a ramp of $2000 \mathrm{rpm}$ per second, using $30 \mathrm{~nm}$ particle paste (Dyesol $30 \mathrm{NR}-\mathrm{D}$ ) diluted in ethanol to achieve a $150-200 \mathrm{~nm}$ thick layer. After the spin coating, the substrates were immediately dried at $100^{\circ} \mathrm{C}$ for $10 \mathrm{~min}$ and then sintered again at $450^{\circ} \mathrm{C}$ for 30 min under dry air flow. Li-doping of mesoporous $\mathrm{TiO}_{2}$ was accomplished by spin coating a $0.1 \mathrm{M}$ solution of Li-TFSI in acetonitrile at $3000 \mathrm{rpm}$ for $30 \mathrm{~s}$ followed by another sintering step at $450^{\circ} \mathrm{C}$ for 30 minutes. After cooling down to $150^{\circ} \mathrm{C}$ the substrates were immediately transferred in a nitrogen atmosphere glove box for depositing the perovskite films.

Perovskite precursor solution and film preparation The organic cations were purchased from Dyesol; the lead compounds from TCI; CsI from abcr GmbH. The perovskite precursor were dissolved in anhydrous DMF:DMSO 4:1 (v:v). We note that $10 \%$ excess $\mathrm{PbI}_{2}$ and $\mathrm{PbBr}_{2}$ are used for perovskite precursor solution. The perovskite solution was spin coated in a two steps program at 1000 and $4000 \mathrm{rpm}$ for 10 and $20 \mathrm{~s}$ respectively. During the second step, $200 \mu \mathrm{L}$ of chlorobenzene was poured on the spinning substrate $15 \mathrm{~s}$ prior to the end of the program. The substrates were then annealed at $100^{\circ} \mathrm{C}$ for $30 \mathrm{~min}$ in a nitrogen filled glove box (only for the device with annealed perovskite). 


\section{WILEY-VCH}

Hole transporting layer and top electrode After the perovskite annealing, the substrates were cooled down for few minutes and a spiro-OMeTAD (Merck) solution (70 $\mathrm{mM}$ in chlorobenzene) was spin coated at $4000 \mathrm{rpm}$ for $20 \mathrm{~s}$. Spiro-OMeTAD was doped with bis(trifluoromethylsulfonyl)imide lithium salt (Li-TFSI, Sigma-Aldrich), tris(2-(1H-pyrazol1-yl)-4-tert-butylpyridine)- $\quad$ cobalt(III) tris(bis(trifluoromethylsulfonyl)imide) $\quad$ (FK209, Dynamo) and 4-tert-Butylpyridine (TBP, Sigma-Aldrich). The molar ratio of additives for spiro-OMeTAD was: 0.5, 0.03 and 3.3 for Li-TFSI, FK209 and TBP respectively. Finally, 70$80 \mathrm{~nm}$ of gold top electrode was thermally evaporated under high vacuum.

Photovoltaic device testing The solar cells were measured using a $450 \mathrm{~W}$ xenon light source (Oriel). The spectral mismatch between AM1.5G and the simulated illumination was reduced by the use of a Schott K113 Tempax filter (Präzisions Glas \& Optik GmbH). The light intensity was calibrated with a Si photodiode equipped with an IR-cutoff filter (KG3, Schott), and it was recorded during each measurement. Current-voltage characteristics of the cells were obtained by applying an external voltage bias while measuring the current response with a digital source meter (Keithley 2400). The voltage scan rate was $10 \mathrm{mV} \mathrm{s}^{-1}$ and no device preconditioning, such as light soaking or forward voltage bias applied for long time, was applied before starting the measurement. The starting voltage was determined as the potential at which the cells furnish $1 \mathrm{~mA}$ in forward bias, no equilibration time was used. The cells were masked with a black metal mask $\left(0.1225 \mathrm{~cm}^{2}\right)$ to fix the active area and reduce the influence of the scattered light. The current was matched according to the intensity of the light source.

Perovskite characterization A ZEISS Merlin HR-SEM was used to characterize the morphology of the device top view and cross-section. X-ray diffraction (XRD) were recorded on an X'Pert MPD PRO (Panalytical) equipped with a ceramic tube ( $\mathrm{Cu}$ anode, $\lambda=1.54060$ 


\section{WILEY-VCH}

$\AA$ ), a secondary graphite (002) monochromator and a RTMS X'Celerator (Panalytical).in an angle range of $2 \theta=5^{\circ}$ to $40^{\circ}$ under ambient condition. Absorption spectral measurements were recorded using Varian Cary5 UV-visible spectrophotometer. Photoluminescence spectra were obtained with Florolog 322 (Horiba Jobin Ybon Ltd) with the range of wavelength from 620 to $850 \mathrm{~nm}$ by exciting at $460 \mathrm{~nm}$. The samples were mounted at $60^{\circ}$ and the emission recorded at $90^{\circ}$ from the incident beam path. For Thermogravimetric analyses (TGA) were carried out using a PerkinElmer TGA4000 with the perovskite powders were gathered from perovskite films which were prepared as same method for devices. The measurements were carried out under dry nitrogen at $20 \mathrm{ml} \mathrm{min}^{-1}$ by heating $5^{\circ} \mathrm{C} \min ^{-1}$. FTIR spectrometer with attenuated total reflectance (ATR) collected by Digilab FTS 7000 spectral data for perovskite precursor in DMF/DMSO (4:1) as liquid phase without dilution.

\section{Supporting Information}

Supporting Information is available from the Wiley Online Library or from the author.

\section{Acknowledgements}

MG thanks the financial support from the Swiss National Science Foundation, the SNSFNanoTera (SYNERGY) and Swiss Federal Office of Energy (SYNERGY), CCEM-CH in the 9th call proposal 906: CONNECT PV, the SNSF NRP70 "Energy Turnaround", the King Abdulaziz City for Science and Technology (KACST) and the European Union's Horizon 2020 research and innovation programme under the grant agreement No 687008 is gratefully acknowledged. The information and views set out in this article are those of the author(s) and do not necessarily reflect the official opinion of the European Union. Neither the European Union institutions and bodies nor any person acting on their behalf may be held responsible for the use which may be made of the information contained herein. M. S. acknowledges support from the co-funded Marie Skłodowska Curie fellowship, H2020 Grant agreement no. 665667. We thank Dr.Kurt for experimental help and fruitful discussion.

Received: ((will be filled in by the editorial staff))

Revised: ((will be filled in by the editorial staff)) Published online: ((will be filled in by the editorial staff)) 


\section{WILEY-VCH}

[1] NREL chart, http://www.nrel.gov/ncpv/images/efficiency_chart.jpg, Accessed 06.10.2016.

[2] K. Masuko, M. Shigematsu, T. Hashiguchi, D. Fujishima, M. Kai, N. Yoshimura, T. Yamaguchi, Y. Ichihashi, T. Mishima, N. Matsubara, T. Yamanishi, T. Takahama, M. Taguchi, E. Maruyama, S. Okamoto, Ieee J Photovolt 2014, 4, 1433-1435.

[3] A. Dualeh, N. Tetreault, T. Moehl, P. Gao, M. K. Nazeeruddin, M. Gratzel, Adv Funct Mater 2014, 24, 3250-3258.

[4] J. W. Lee, D. J. Seol, A. N. Cho, N. G. Park, Adv Mater 2014, 26, 4991-4998.

[5] N. J. Jeon, J. H. Noh, W. S. Yang, Y. C. Kim, S. Ryu, J. Seo, S. I. Seok, Nature 2015, $517,476-480$.

[6] J. Troughton, C. Charbonneau, M. J. Carnie, M. L. Davies, D. A. Worsley, T. M. Watson, J Mater Chem A 2015, 3, 9123-9127.

[7] J. Troughton, M. J. Carnie, M. L. Davies, C. Charbonneau, E. H. Jewell, D. A. Worsley, T. M. Watson, J Mater Chem A 2016, 4, 3471-3476.

[8] J. W. Lee, D. H. Kim, H. S. Kim, S. W. Seo, S. M. Cho, N. G. Park, Adv Energy Mater 2015, 5.

[9] M. Saliba, T. Matsui, J.-Y. Seo, K. Domanski, J.-P. Correa-Baena, M. K. Nazeeruddin, S. M. Zakeeruddin, W. Tress, A. Abate, A. Hagfeldt, M. Gratzel, Energ Environ Sci 2016.

[10] Y. Zhou, M. Yang, W. Wu, A. L. Vasiliev, K. Zhu, N. P. Padture, J Mater Chem A 2015, 3, 8178-8184.

[11] M. Yin, F. Xie, H. Chen, X. Yang, F. Ye, E. Bi, Y. Wu, M. Cai, L. Han, J Mater Chem A 2016, 4, 8548-8553.

[12] M. Saliba, S. Orlandi, T. Matsui, S. Aghazada, M. Cavazzini, J.-P. Correa-Baena, P. Gao, R. Scopelliti, E. Mosconi, K.-H. Dahmen, F. De Angelis, A. Abate, A. Hagfeldt, G. Pozzi, M. Graetzel, M. K. Nazeeruddin, Nature Energy 2016, 1, 15017.

[13] D. Bi, W. Tress, M. I. Dar, P. Gao, J. Luo, C. Renevier, K. Schenk, A. Abate, F. Giordano, J. P. Correa Baena, J. D. Decoppet, S. M. Zakeeruddin, M. K. Nazeeruddin, M. Gratzel, A. Hagfeldt, Sci Adv 2016, 2, e1501170.

[14] Y. C. Kim, N. J. Jeon, J. H. Noh, W. S. Yang, J. Seo, J. S. Yun, A. Ho-Baillie, S. J. Huang, M. A. Green, J. Seidel, T. K. Ahn, S. Il Seok, Adv Energy Mater 2016, 6.

[15] W. S. Yang, J. H. Noh, N. J. Jeon, Y. C. Kim, S. Ryu, J. Seo, S. I. Seok, Science 2015, 348, 1234-1237.

[16] J. Pan, C. Mu, Q. Li, W. Li, D. Ma, D. Xu, Adv Mater 2016, n/a-n/a.

[17] S. Bae, S. J. Han, T. J. Shin, W. H. Jo, J Mater Chem A 2015, 3, 23964-23972.

[18] Y. G. Rong, Z. J. Tang, Y. F. Zhao, X. Zhong, S. Venkatesan, H. Graham, M. Patton, Y. Jing, A. M. Guloy, Y. Yao, Nanoscale 2015, 7, 10595-10599.

[19] D. P. Nenon, J. A. Christians, L. M. Wheeler, J. L. Blackburn, E. M. Sanehira, B. J. Dou, M. L. Olsen, K. Zhu, J. J. Berrya, J. M. Luther, Energ Environ Sci 2016, 9 , 2072-2082.

[20] N. Ahn, D.-Y. Son, I.-H. Jang, S. M. Kang, M. Choi, N.-G. Park, J Am Chem Soc 2015, 137, 8696-8699.

[21] T. Glaser, C. Müller, M. Sendner, C. Krekeler, O. E. Semonin, T. D. Hull, O. Yaffe, J. S. Owen, W. Kowalsky, A. Pucci, R. Lovrinčić, The Journal of Physical Chemistry Letters 2015, 6, 2913-2918.

[22] X. Guo, C. McCleese, C. Kolodziej, A. C. S. Samia, Y. Zhao, C. Burda, Dalton Transactions 2016, 45, 3806-3813.

[23] D. Shen, X. Yu, X. Cai, M. Peng, Y. Ma, X. Su, L. Xiao, D. Zou, J Mater Chem A 2014, 2, 20454-20461.

[24] N. J. Jeon, J. H. Noh, Y. C. Kim, W. S. Yang, S. Ryu, S. I. Seok, Nat Mater 2014, 13, 897-903. 


\section{WILEY-VCH}

[25] J. P. C. Baena, L. Steier, W. Tress, M. Saliba, S. Neutzner, T. Matsui, F. Giordano, T. J. Jacobsson, A. R. S. Kandada, S. M. Zakeeruddin, A. Petrozza, A. Abate, M. K. Nazeeruddin, M. Gratzel, A. Hagfeldt, Energ Environ Sci 2015, 8, 2928-2934. 
(a)

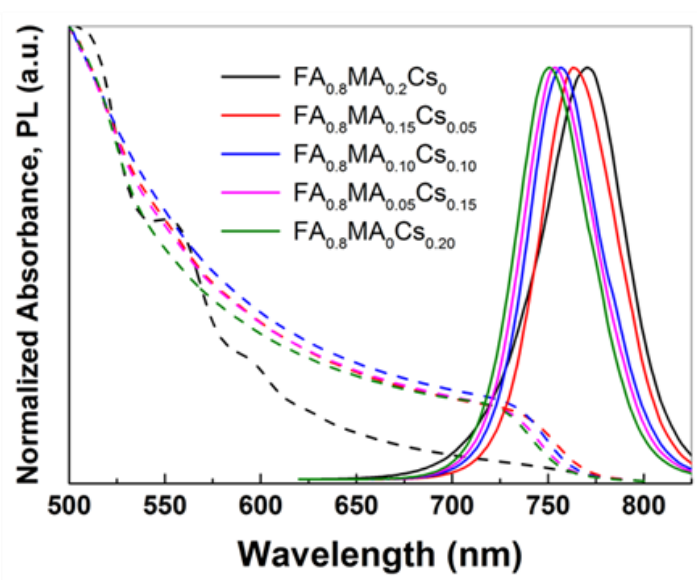

(c)

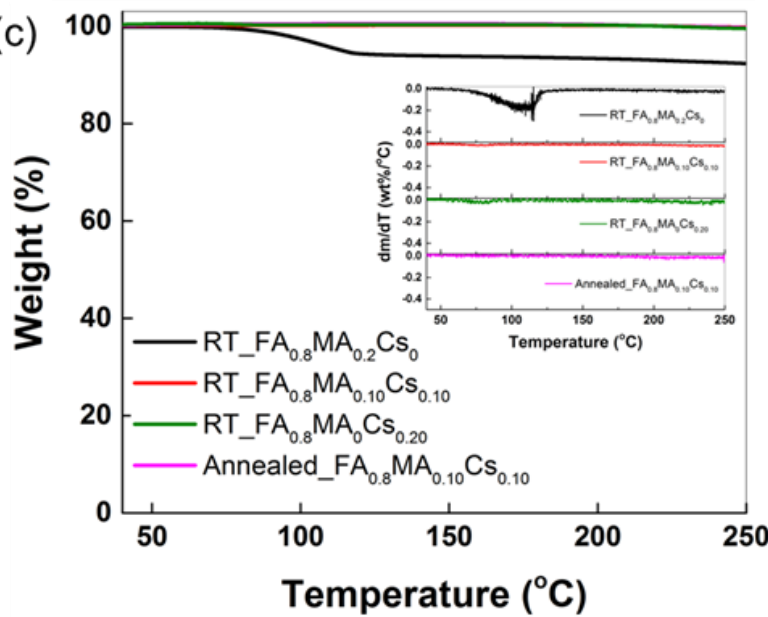

(b)

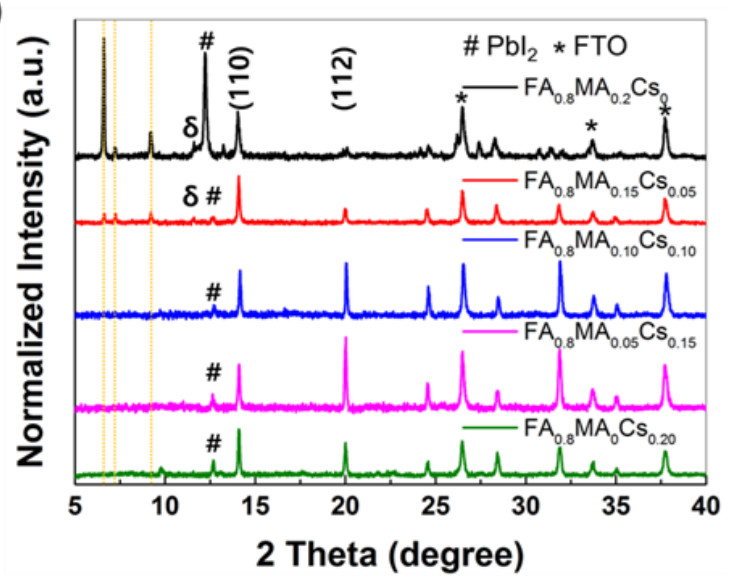

(d)

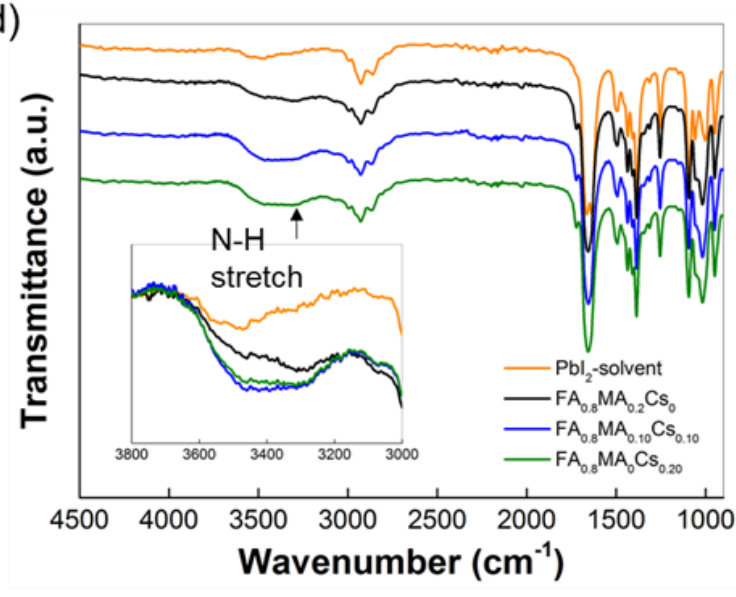

Figure 1. Optical measurement and XRD analysis for room temperature (RT) prepared $\mathrm{FA}_{0.8} \mathrm{MA}_{0.2-\mathrm{x}} \mathrm{Cs}_{\mathrm{x}}$ films of varying Cs content $\mathrm{x}$. (a) PL spectra and UV-vis absorption spectra (dashed line) of the films. (b) XRD data the orange colored dashed vertical lines in the XRD spectrum indicate the peak positions of the $\mathrm{MA}_{2} \mathrm{~Pb}_{3} \mathrm{I}_{8} \cdot 2 \mathrm{DMSO}$ intermediate phase. The data of annealed films can be found in figure S1. (c) TGA curves and their first derivatives (insert) of $\mathrm{FA}_{0.8} \mathrm{MA}_{0.2-\mathrm{x}} \mathrm{Cs}_{\mathrm{x}}$ powder. Heating rate is $5^{\circ} \mathrm{C} / \mathrm{min}$ (d) Fourier transform infrared spectrometer (FTIR) spectra of perovskite solution of $\mathrm{FA}_{0.8} \mathrm{MA}_{0.2-\mathrm{x}} \mathrm{Cs}_{\mathrm{x}}$. Insert shows enlarged curves in the range from $3800 \mathrm{~cm}^{-1}$ to $3000 \mathrm{~cm}^{-1}$. 


\section{WILEY-VCH}

(a) Two step

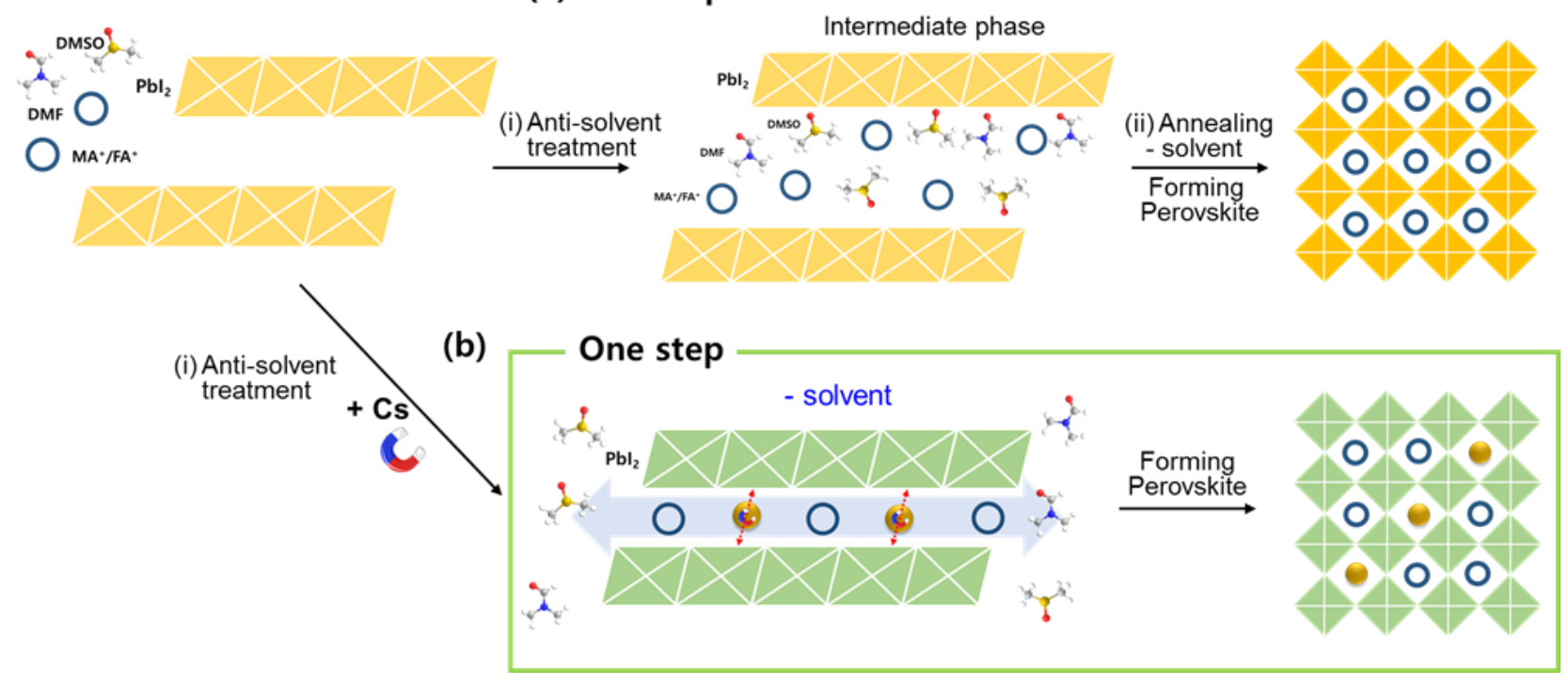

Scheme 1. Illustration of different procedures for crystalline perovskite film formation by solution processing. (a) conventional two step method with annealing. (i) intermediate phase of $\mathrm{MA}_{2} \mathrm{~Pb}_{3} \mathrm{I}_{8} \cdot 2 \mathrm{DMSO}$ is formed with edge-sharing $\left[\mathrm{PbI}_{6}\right]^{4-}$ octahedral layers after antisolvent treatment to FA/MA (without Cs). (ii) intermediate phase is converted to perovskite phase via solvent/cation exchange between octahedral layers after thermal annealing (b) one step method without annealing with Cs (i) Cs is intercalated and pushes out solvent molecules from between the $\left[\mathrm{PbI}_{6}\right]^{4-}$ octahedral layers since the intermolecular interaction of $\mathrm{Cs}-\left[\mathrm{PbI}_{6}\right]^{4-}$ is strong enough to remove the solvents. It allows forming crystalline perovskite phase without annealing. 


\section{WILEY-VCH}

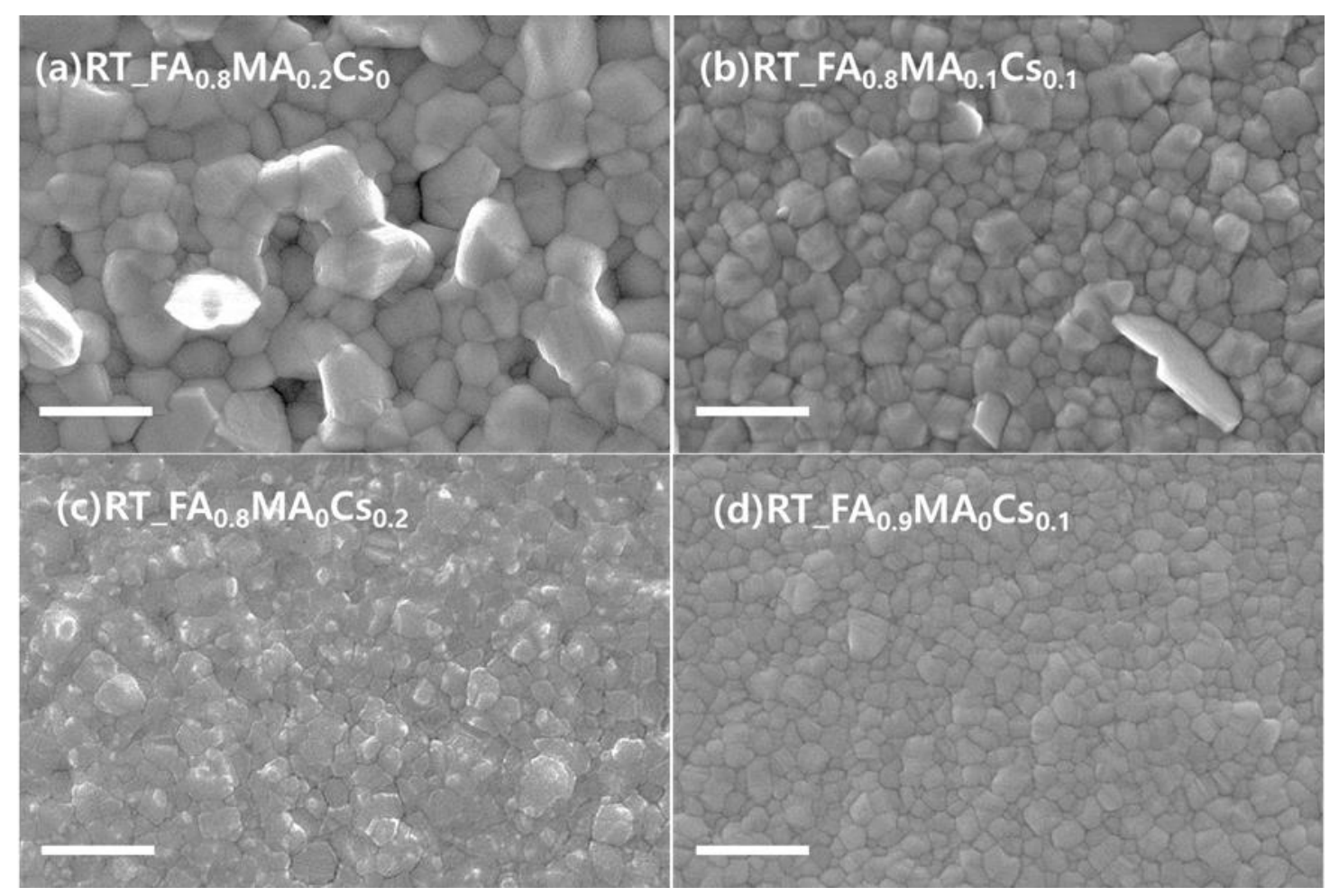

Figure 2. SEM image of perovskite films (a)FA $\mathrm{FA}_{0.8} \mathrm{MA}_{0.2} \mathrm{Cs}_{0} \quad$ (b) $\mathrm{FA}_{0.8} \mathrm{MA}_{0.1} \mathrm{Cs}_{0.1}$ (c) $\mathrm{FA}_{0.8} \mathrm{MA}_{0} \mathrm{Cs}_{0.2}(\mathrm{~d}) \mathrm{FA}_{0.9} \mathrm{MA}_{0} \mathrm{Cs}_{0.1}$ before annealing (Scale bar is $500 \mathrm{~nm}$ ). 


\section{WILEY-VCH}

(a)

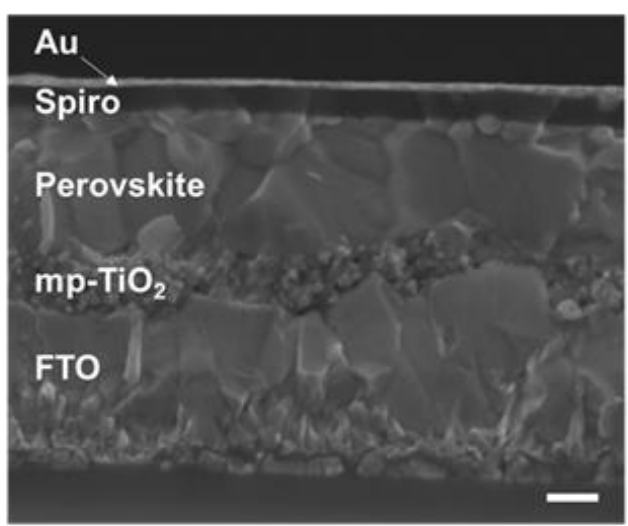

(c)

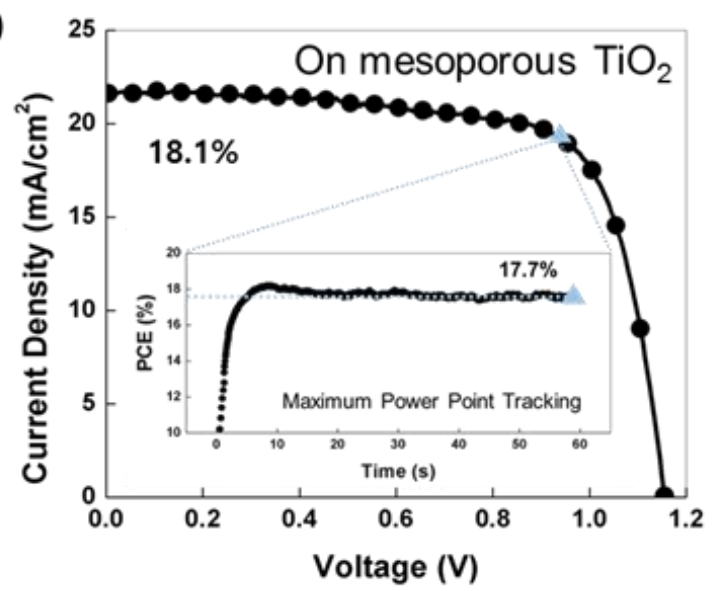

(b)

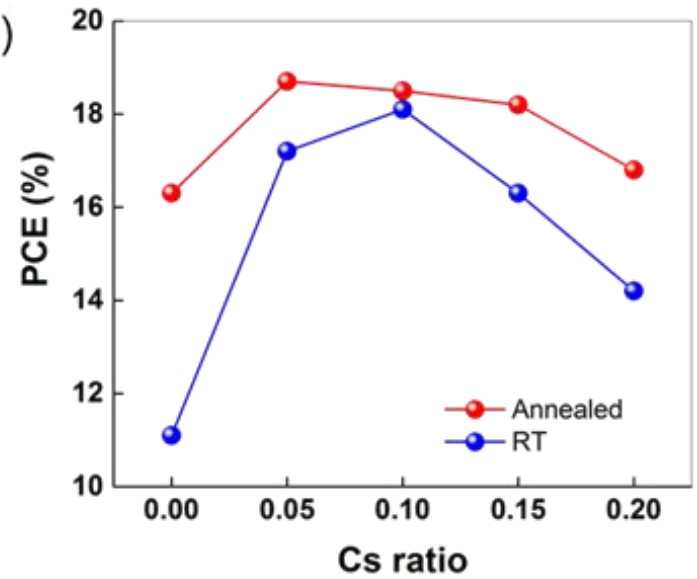

(d)

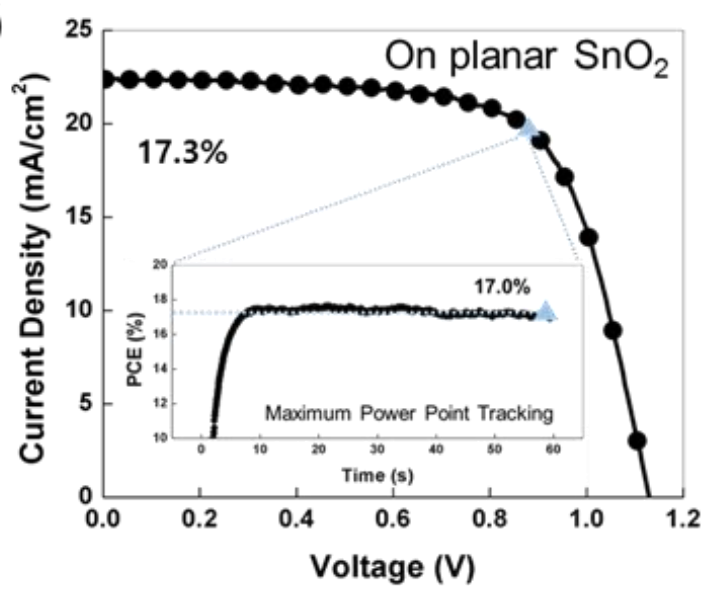

Figure 3 (a) Cross sectional SEM image of the $\mathrm{FA}_{0.8} \mathrm{MA}_{0.1} \mathrm{Cs}_{0.1}$ device without annealing. Scale bar is $200 \mathrm{~nm}$ (b) Effect off the MA/Cs ratio on the PCE for annealed and un-annealed devices. $\mathrm{J}-\mathrm{V}$ curve and maximum power point tracking of the champion $\mathrm{FA}_{0.8} \mathrm{MA}_{0.1} \mathrm{Cs}_{0.1}$ device without annealing on (c) mesoporous $\mathrm{TiO}_{2}$ (d) planar $\mathrm{SnO}_{2}$. Devices were masked with an aperture of $0.1225 \mathrm{~cm}^{2}$ to define the active area. Incident photon to current efficiency (IPCE), hysteresis behaviour and statistic data can be found in Figure S4-S6. 


\section{WILEY-VCH}

A room-temperature perovskite material yielding a power conversion efficiency of $\mathbf{1 8 . 1 \%}$ (stabilized at $\mathbf{1 7 . 7 \%}$ ) is demonstrated by judicious selection of the cations. Both Cs and MA is necessary for room-temperature FA based perovskite to obtain the photoactive crystalline perovskite phase and high quality crystals. This room-temperature made perovskite material shows great potential for low-cost, large-scale manufacturing such as roll-to-roll process.

Keyword perovskite solar cells, room temperature perovskite

Taisuke Matsui ${ }^{a}{ }_{\dagger}, J i-Y o u n$ Seo ${ }^{b} \dagger$, Michael Saliba ${ }^{b}$, Shaik M Zakeeruddin ${ }^{b}$ and Michael Grätzel $^{b^{*}}$

Room-temperature formation of highly crystalline multication perovskites for efficient, low-cost solar cells

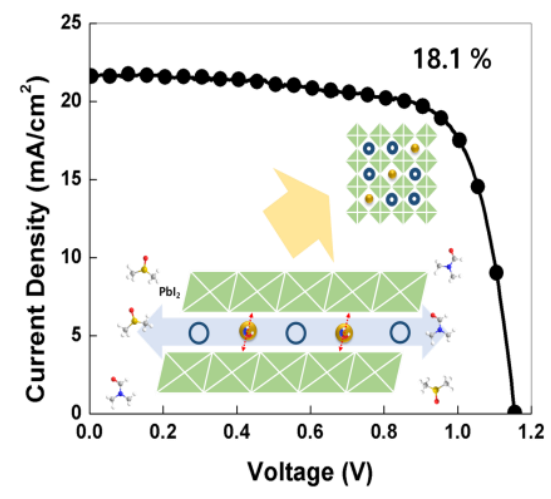

